\title{
Experimental characterization of an unglazed transpired solar collector
}

\author{
Messaoud Badache, Daniel R. Rousse*, and Stéphane Hallé \\ École de technologie supérieure, T3E Industrial Research Chair, Montreal, Canada, H3C 1K3 \\ *Corresponding author: daniel@t3e.info
}

\begin{abstract}
This work presents an experimental methodology used to characterize the thermal performances of unglazed transpired collectors (UTC). The main relevant parameters that were measured are: the absorber plate temperature, the ambient temperature, and the air outlet temperature. As a general conclusion, it was found that an increase in irradiation has about twice the impact on the thermal performances of any of the panel investigated parameters than the diameter of the perforations. Ongoing research is now carried out with actual and potential Canadian manufacturers to improve the design methodology and optimize this type of collector to eastern Canada climate.
\end{abstract}

\section{Introduction}

Two of the most promising applications of solar thermal energy concern the supply of hot air for drying and heating [1]. Whereas drying of agricultural, textile or marine products could be interesting in the tropical regions or even 30 to 40 degrees above or below the equator in specific areas, space heating of buildings to maintain a comfortable environment in the winter season (actually preheating of ventilation air) is the most interesting application in Canada. To fulfill these needs, several designs for solar air heaters have been proposed and discussed in the literature.

In the US, the group lead by Kutscher [2-5], who deposited his Ph.D. dissertation in 1992, has been involved until very recently on a particular type of plate solar collector: the unglazed transpired solar collectors (UTC) also called the perforated collectors. The unglazed transpired solar collector is a dark, perforated vertical/inclined sheet metal absorber fixed to another parallel surface or wall, with a gap of $10-15 \mathrm{~cm}$ between them; all sides being closed and sealed. Ambient air, pulled through the perforations with a fan, absorbs the heat the absorber surface and is heated in the process. These collectors reportedly offer the lowest cost and highest efficiency (60-75\%) for air heating [3].

In Canada, the research group of Hollands from the University of Waterloo has been working extensively, mostly between 1990 and about 2000 on such collectors [6, 7]. This work lead to the design and patent of the SOLARWALLC [8]. As of 2010, Conserval Engineering [8] claims that it supplied and designed over 3 million square feet $\left(278000 \mathrm{~m}^{2}\right)$ of its systems in 30 countries. In 2011, the Canadian patent of the SOLARWALLO (the Canadian UTC) will expire. Consequently, the interest is boosted among the practitioners and academics since Canada has a climate tailored for such air preheating devices.

Hence, the subject matter of this paper is the experimental characterization of UTC in the context of preheating ventilation air. The thermal efficiency, $\eta$, depends on the total hemispherical absorptivity of the absorber plate, the wind speed, the suction velocity and the plate geometry. In this study, we will focus on the plate absortivity, perforation diameter, irradiation, and mass flow rate. 
The objectives were to: (1) design, built, and evaluate a first UTC prototype upon which several elementary tests were to be carried out; (2) evaluate the performance of three different absorber plate coatings for several conditions; (3) propose a first experimental project upon which further projects will be build.

\section{Energy balance and efficiency of the UTC}

The investigated configuration is schematically described in Fig. 1(a). On the left-hand side, the artificial source of radiation (discussed later) is depicted while the thermal collector is shown on the right-hand side. The important variables here are the ambient temperature, $T_{\mathrm{amb}}$, the collector average temperature, $T_{\text {abs }}$, and the outlet temperature, $T_{\text {out }}$, that will be used to compute $\eta_{\text {coll }}$. The mass flow rate is also a predominant variable that must be measured.

Fig.1(b) shows the overall energy balance on both the absorber plate and the plenum. To establish such a balance several assumptions were formulated.

\subsection{The working assumptions}

To permit an analysis of the UTC's efficiency, several assumptions have to be formulated: (1) the mass flow rate through the perforation is assumed to be homogeneous; (2) the reverse flow across the perforation is neglected; (3) the absorber plate is considered to be diffuse and gray; (4) losses along the plenum edge are neglected; (5) the absorber and back plate temperatures are assumed to be isothermal throughout their respective surfaces and thicknesses; (6) convection losses from the plate to the environment are considered negligible; (7) air thermophysical properties are assumed to be constant and evaluated at an average temperature $\left(T_{\mathrm{amb}}+T_{\text {out }}\right) / 2 ;(8)$ the back plate is perfectly insulated.

These assumptions are consistent with studies carried-out earlier [2, 4] and are discussed in [9].

\subsection{The energy balance}

Overall, the thermal measurements allowed computing the thermal power of the unit which is simply obtained from the incident solar (artificial) radiation minus all types of heat losses. Strictly, one could establish an energy balance on the absorber plate, on the plenum air, and on the back plate (which is neglected here). These balances call for the evaluation of radiative and convective heat fluxes. But here, the sole interest is the efficiency of the collector defined such as:

$$
\eta_{\text {coll }}=\frac{\dot{m}_{\text {out }} c_{p}\left(T_{\text {out }}-T_{\text {amb }}\right)}{G_{T} A_{\text {coll }}}
$$

The efficiency is then the ratio of the useful recovered power, $Q_{\text {util }}$, to the total (artificial) solar power input on the surface.

\section{Experimental apparatus}

The experimental apparatus involves three main parts: the perforated collector; the air collecting and exhausting system; and the solar simulator. 


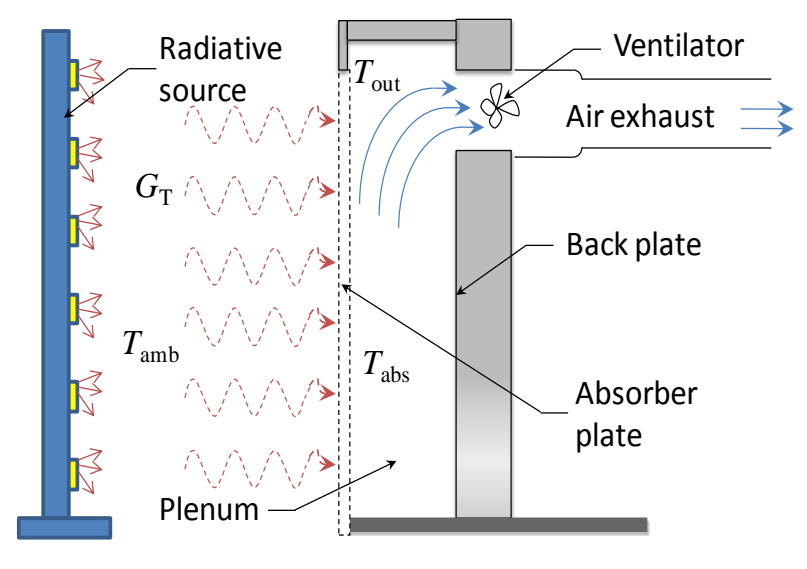

(a)

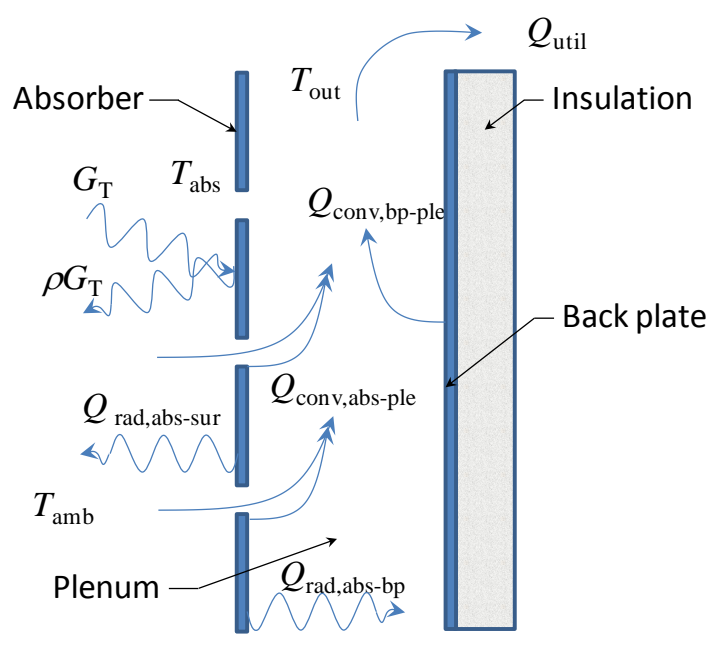

(b)

Fig. 1: (a) Schematic of the experimental apparatus; (b) energy balance on the collector.

\subsection{The perforated collector}

The perforated collector has been designed and constructed at CTT-ETS. It is designed to be installed vertically and involves the absorber plate itself, the back plate, and the insulation layer. The overall size is $1.778 \mathrm{~m} \times 0.60 \mathrm{~m} \times 0.15 \mathrm{~m}$ based on the study of Kutscher [2]. The back plate of the apparatus involves a horizontal slot to suck the air into an horizontal duct into which the mass flow rate is measured. The external surface of the collector (absorber plate) is made of galvanized steel. Thirtyeight $\mathrm{mm}\left(1 \frac{1}{2}\right.$ ") of polystyrene provide the appropriate insulation. The overall thermal resistance is estimated to be equal to $1.2 \mathrm{~m}^{2} \mathrm{~K} / \mathrm{W}$. The whole apparatus is fixed on a wooden base designed for positioning and moving the collector while ensuring stability. The rear part, the bottom, the top, and the sides are insulated. The whole collector also enables installation as a part of a wall.

With respect to former studies [2, 6, 7], a triangular (staggered) pattern was chosen for perforations with a $24.5 \mathrm{~mm}$ pitch. Three different galvanized steel absorbers were used for the tests: the first was coated with non reflective black paint from the market; the second plate was covered with Thurmalox 250 selective black coating (Dampney); and the third plate was left untreated.

\subsection{The ventilation air system}

The plenum thickness is $15 \mathrm{~cm}$ and a $160 \mathrm{CFM}\left(75.5 \mathrm{~L} \mathrm{~s}^{-1}\right)$ axial inline duct ventilator (DB206) is used [4]. The ventilator creates a negative pressure in the plenum, drawing heated air through the perforations. A variable drive (3PN116B, 110/120 V, 60Hz) ensures proper control. An exhaust pipe (15 cm OD, $1.5 \mathrm{~m}$ length) was added to remove the heat away from the unit to avoid any thermal contamination of the experiment.

\subsection{The radiative heat source}

The artificial solar simulator involves 28 globe ${ }^{\circledR}-6550$ projectors with T3/J-TYPE $/ 78 \mathrm{~mm}, 150$ Watts, bulbs that collectively provide a total radiative intensity of $4.2 \mathrm{~kW}$. Metal Halide Short Arc lamps were first selected as their spectrum is close to that of the sun. However, these lamps could not be used 
since our lab would have required major modifications (Security and air conditioning). Instead, classical halogen lamps producing an irradiation between 300 and $700 \mathrm{~W} / \mathrm{m}^{2}$ were selected as they provide a spectrum close to that of a black body at $3500 \mathrm{~K}$.

The spectral distribution of the irradiation $G$ is sufficiently close to that of the Sun as its maximum emission occurs at $\lambda=0.8 \mu \mathrm{m}$ while that of the sun is at $\lambda=0.5 \mu \mathrm{m}$. Indeed, on the range $0.4<\lambda<0.9$ $\mu \mathrm{m}$, the absorber plate is assumed to have constant properties.

The European standard described by the CSTB [10] was observed to ensure proper installation of our own facility.

\section{Experimental measurements}

The instrumentation used permitted to obtain:

- The total hemispherical irradiation received by the absorber plate, $G_{\mathrm{T}}$;

- The relevant temperatures, $T_{\mathrm{amb}}, T_{\mathrm{abs}}, T_{\mathrm{out}}$;

- The mass flow rate at the exit off the duct ventilator, $\dot{m}_{\text {out }}$.

\subsection{The irradiation measurement}

A Kipp \& Zonen CMP11 pyranometer $\left( \pm 7 \mathrm{~W} / \mathrm{m}^{2}\right.$ ) involving a 32 junctions thermopile was used to evaluate the irradiation provided by the lamps. This pyranometer may be used either with a multimeter or data acquisition system. It is a class 1 instrument according to the WMO (ISO 9060). It's normal sensitivity is $S=9.17 \mu \mathrm{V} /\left(\mathrm{W} / \mathrm{m}^{2}\right)$. As in other such instruments, the irradiation, $G_{\mathrm{T}}$, incident on the absorber plate can be obtained by dividing the output tension signal, $U_{\text {emf }}$, by the nominal sensitivity, $S$, of the device. The uncertainty on this measurements is taken as $\Delta G_{\mathrm{T}} / G_{\mathrm{T}}=0.01$.

Standard care has to be taken with de device, that is: (1) the glass must be clean and scratches free; (2) the desiccant must be examined to avoid humidity; (3) parallelism must be ensured between the plane of the device and that of the absorber; and (4) geometrical caution has to be taken to ensure that the device receives the same power than the absorber plate.

\subsection{The mass flow rate}

Hot wire anemometry (TSI, Velocicalc 8347) was used to measure air velocities. This very sensitive probe, both for temperature and velocity, allows measurements in the range $0 \mathrm{~m} / \mathrm{s}$ to $30 \mathrm{~m} / \mathrm{s}$ with an uncertainty of $3 \%$ of reading or $\pm 0.015 \mathrm{~m} / \mathrm{s}$ whichever is greater. A typical velocity obtained was about $2 \mathrm{~m} / \mathrm{s}$ for the maximum pressure drop. To obtain the mass flow rate, the mean velocity, $\bar{V}$, in the fully developed region of the exhaust pipe is obtained from the average of the velocity measured at the pipe axis and the velocity measured at the a point located between the pipe axis and the solid surface. The velocity $\bar{V}$ is multiplied by the air density, $\rho$, at $T_{\text {out }}$, and by the cross section surface area, $A_{\mathrm{cs}}$. Since the flow is fully turbulent, the velocity profile is fairly flat across the pipe section. The uncertainty on this measurements is taken $\Delta V / V=0.03$. The uncertainty on $\rho$ is assumed to be $\Delta \rho / \rho=0.02$ and that on the surface area is $\Delta A_{\mathrm{cs}} / A_{\mathrm{cs}}=0.01$ for a total uncertainty on the mass flow rate of $\Delta \dot{m}_{\text {out }} / \dot{m}_{\text {out }}=0.04$. 


\subsection{The temperature}

Three types of temperature measurements were necessary for the experiments: (1) the ambient air temperature, $T_{\mathrm{amb}}$; the outlet air temperature, $T_{\text {out }}$, and the absorber surface temperature, $T_{\mathrm{abs}}$. In all cases, temperature was measured with 29 calibrated Omega K-type thermocouples. The uncertainty on this measurements is $\Delta T / T=0.02$. Their dynamic range $\left(0-1370^{\circ} \mathrm{C}\right)$ is more than needed. Calibration has been carried out only in the range $0-50^{\circ} \mathrm{C}$. The temperature measurement spatial distribution was as follows: 24 evenly spaced thermocouples were bonded to the inner surface of the absorber plate (to verify the isothermal assumption) measuring, $T_{\mathrm{abs}}$; one thermocouple was measuring the air temperature in front of the unit, $T_{\mathrm{amb}}$ (this thermocouple was shielded from the lamps); one was measuring air temperature behind the unit (to evaluate whether or not the one in the front was biased by the radiative flux); another thermocouple was measuring the temperature at the exhaust inlet (before the fan) $T_{\text {out }}$, another one was located in the fully developed region, downstream in the exhaust to estimate the density, one far away from the apparatus in the lab; and a final one just outside the exhaust. A complete view will be given on the poster.

\section{Results and discussions}

The results are presented here in terms of the variation of the collectors efficiency, $\eta_{\text {coll }}$, as a function of the mass flow rate. These results are presented for three different absorber plates and selected values of the perforations diameter $(1.5 ; 2.0 ; 2.4 \mathrm{~mm})$, the irradiation $\left(350 ; 400 ; 600 \mathrm{~W} / \mathrm{m}^{2}\right)$, and the mass flow rate $(0.01 ; 0.02 ; 0.03 \mathrm{~kg} / \mathrm{s})$. The uncertainty on the efficiency $\Delta \eta_{\text {coll }}$ is obtained from the sum of the uncertainties on the measurements of the mass flow rate, $\Delta \dot{m}_{\text {out }} / \dot{m}_{\text {out }}$, the temperature, $\Delta T / T$, (twice), and the irradiation, $\Delta G_{\mathrm{T}} / \mathrm{G}_{\mathrm{T}}$. This uncertainty is accounted for by error bars on the following graphs and $\Delta \eta_{\text {coll }} / \eta_{\text {coll }}=0.05$

First, we validated our assumptions. Systematically, the inner temperatures (temperatures closer to the center of the absorber plates) were always about $2^{\circ} \mathrm{C}$ higher than the temperature close to the edges. Hence, the assumption that the absorber and back plate temperatures are isothermal throughout their respective surfaces and thicknesses was not validated. Nevertheless, the average temperature was used as $T_{\text {abs. }}$.

Second, without flow, the three absorbers reach equilibrium state such as given in Table 1. It is worth noting that the equilibrium temperature is far from a monotonic decrease with $G$. The parameter of interest here was the temperature difference $\left(T_{\mathrm{abs}}-T_{\mathrm{amb}}\right)$ rather than $T_{\mathrm{abs}}$ itself as $T_{\mathrm{amb}}$ had been quite different from one day to the next in the lab. Moreover, it was found that the use of the source over extended periods modified the ambient temperature although an exhaust was used for the air. This suggests that the reflected portion of the irradiation was reabsorbed by the lab environment.

\subsection{The type of absorber}

Figure 2 shows results for the three absorber plates, a fixed perforation diameter of $D=1.5 \mathrm{~mm}$, and an irradiation of $G_{\mathrm{T}}=600 \mathrm{~W} / \mathrm{m}^{2}$. At a glance, Figure 2 shows that for all types of absorber plate, the efficiency $\eta_{\text {coll }}$ increases with the mass flow rate. That is there is more and more heat removed from the absorber plate as the flow rate increases. However, one should consider that the efficiency 
presented here does not account for the fan power used to extract the heat and that at high flow rates this power could overwhelm the heat recovery.

Table 1. Equilibrium absorber plates temperatures.

\begin{tabular}{|c|c|c|c|}
\hline Equilibrium temperature, $\boldsymbol{T}_{\text {abs }}\left[{ }^{\mathbf{0}} \mathbf{C}\right]$ & $\boldsymbol{G}_{\mathbf{T}}=\mathbf{6 0 0}\left[\mathbf{W} / \mathbf{m}^{2}\right]$ & $\boldsymbol{G}_{\mathbf{T}}=\mathbf{4 0 0}\left[\mathbf{W} / \mathbf{m}^{2}\right]$ & $\boldsymbol{G}_{\mathbf{T}}=\mathbf{3 5 0}\left[\mathbf{W} / \mathbf{m}^{2}\right]$ \\
\hline Absorber 1 & $36^{\circ} \mathrm{C}$ & $33^{\circ} \mathrm{C}$ & $31^{\circ} \mathrm{C}$ \\
\hline Absorber 2 & $56^{\circ} \mathrm{C}$ & $49^{\circ} \mathrm{C}$ & $46^{\circ} \mathrm{C}$ \\
\hline Absorber 3 & $57^{\circ} \mathrm{C}$ & $50^{\circ} \mathrm{C}$ & $47^{\circ} \mathrm{C}$ \\
\hline
\end{tabular}

The efficiency increases as the source provides enough energy (absorbed accordingly by the absorbers) to sustain a sufficient high outlet air temperature, $T_{\text {out }}$, despite the higher pumping rate. Also, with increasing mass flow rate, the equilibrium temperature of the surface decreases and this restrict the radiative emission from the absorber to the surroundings [4].

The uncoated absorber (denoted abs 1), as expected, shows the worst performance as its absorbtivity in the range $0.4 \mu \mathrm{m}<\lambda<0.9 \mu \mathrm{m}$ is very low compare to the other two. For the ongoing results, abs 1 will not be discussed.

The efficiency of abs 2 and abs 3 are in the same range and globally the three curves presented in Fig. 2 are in good agreement with the equilibrium temperatures presented in Table 1.

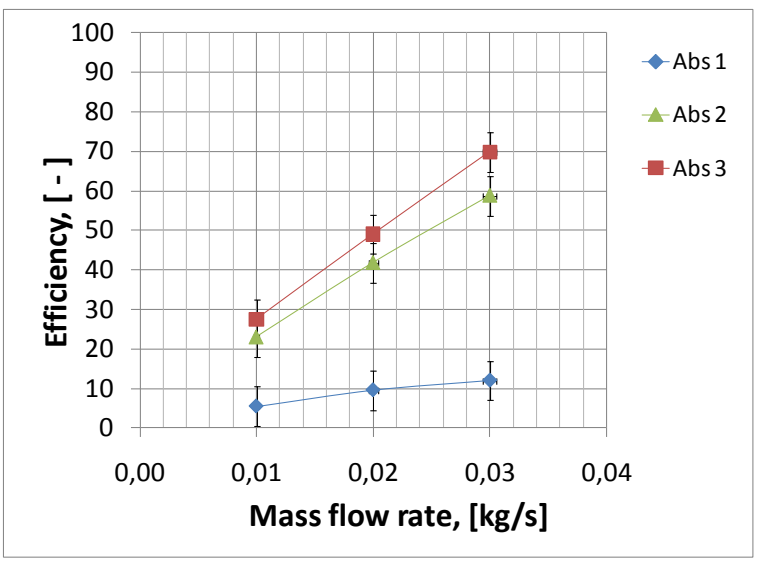

Fig. 2: Efficiency of the absorber as a function of the mass flow rate for the three absorber plates with perforations diameter $D=1.5 \mathrm{~mm}$ and irradiation $G_{\mathrm{T}}=600 \mathrm{~W} / \mathrm{m}^{2}$.

\subsection{The perforation diameter}

Figure 3 explores the variation of the efficiency $\eta_{\text {coll }}$ with the mass flow rate for the three perforation diameters $D=1.5 ; 2.0 ; 2.4 \mathrm{~mm}$ with a fixed irradiation $G_{\mathrm{T}}=600 \mathrm{~W} / \mathrm{m}^{2}$. Fig 3 presents results for the black absorber and shows that for the same mass flow rate, smaller holes induce higher velocities and more heat transfer from the plate to the air with a net impact on the efficiency [6]. For the other two absorbers (results not shown), the perforation diameter had no net effect as all curves more or less collapse to a single one within the uncertainty on the measurements. 


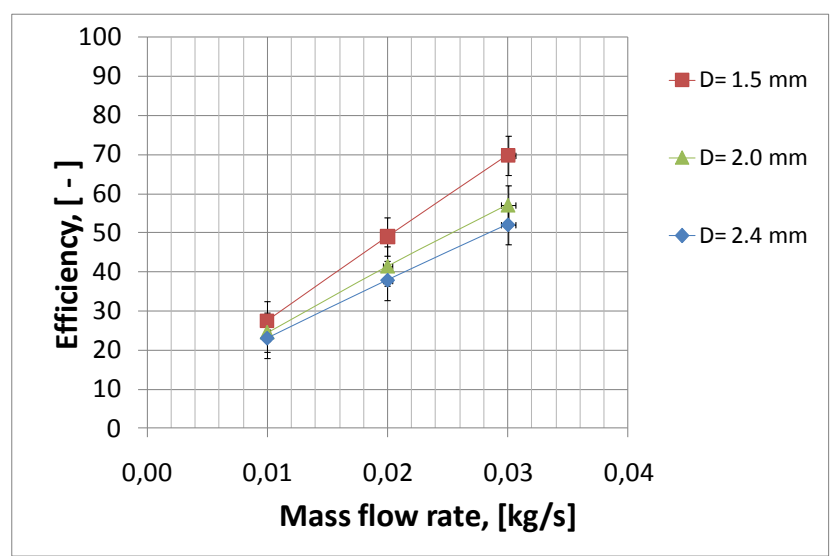

Fig. 3: Efficiency of the black absorber (abs 3) as a function of the mass flow rate for the three different perforation diameters with irradiation $G_{\mathrm{T}}=600 \mathrm{~W} / \mathrm{m}^{2}$.

\subsection{The radiative heat flux}

Figure 4 shows the variation of the efficiency with the mass flow rate for the three values of the irradiation $G_{\mathrm{T}}=600 ; 400$; and $350 \mathrm{~W} / \mathrm{m}^{2}$ with a fixed perforation diameter $D=2.0 \mathrm{~mm}$. Fig 4 presents results for the black absorber and shows that the highest irradiation has the lowest efficiency. This is not surprising as a high irradiation will induce a higher surface temperature and therefore a higher radiative flux from the plate to the surroundings, $Q_{\text {abs-sur }}[4]$. For the other two values of irradiation, the uncertainty on the value of $\eta_{\text {coll }}$ makes it impossible to state anything. A similar behavior was obtained for the selective paint and uncoated surface (not shown). It is worth noting that although a poor efficiency is obtained for the highest flux, the heat recovery, $Q_{\text {util }}$, is higher than for the other two cases.

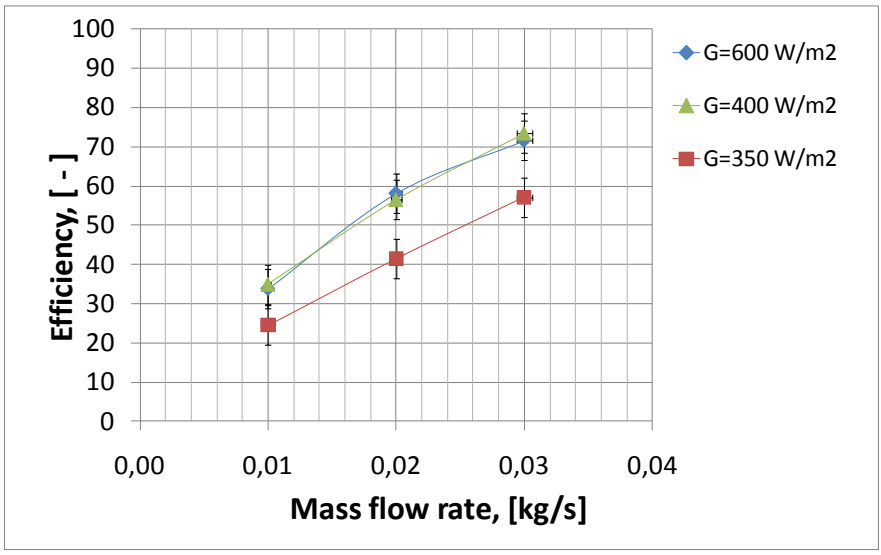

Fig. 4: Efficiency of the black absorber (abs 3) as a function as a function of the mass flow rate for the three different incident irradiation $G_{\mathrm{T}}$ for $D=2.0 \mathrm{~mm}$.

\section{Concluding remarks}

In a lot of its regions, Canada has a climate tailored for solar air preheating devices because of abundant irradiation and high needs for heating. These conditions are even improved in winter when the snow cover boosts the effective irradiance on a vertical wall. As in 2011, the Canadian patent of 
the SOLARWALLO (the Canadian unglazed transpired collector (UTC)) will expire, the interest is boosted among the practitioners and academics for such devices.

This paper presents the first research effort at the Center for Thermal Technologies (CTT) and the Technologies of energy and energy efficiency (T3E) industrial research chair to experimentally characterize unglazed transpired collectors. Here, the variation of the mass flow rate, the incident irradiation, and the perforation diameter were investigated for three types of absorber plate on the collector. It has been found, like in previous studies, that the efficiency decreases with increasing irradiation as the absorber temperature increases and therefore emits more radiation to the surroundings. The increase of the mass flow rate induces a decrease in surface temperature and, consequently, an increase in efficiency. Based on our observations the perforation diameter does not play a preponderant role on the efficiency.

This first study reveals the many difficulties to set-up the experiment in an adequate surrounding. Our future effort will be directed to ensure the surrounding stability. It is also proposed to install collectors in-situ on our Solar House while still carrying experiments in a controlled environment. In both cases, the spectral absorbtivity of the surfaces should also be measured. Finally, a simulation project [5, 11] should start in September 2010 for UTC.

\section{References}

[1] R. Chandra, M.S., Sodha, Testing procedures for solar air heaters: a review. Energy Conversion and Management, 32(1), 1991,11-33.

[2] C.F. Kutscher, An Investigation of Heat Transfer for Air Flow through Low Porosity Perforated Plates. Ph.D. dissertation, University of Colorado, Department of Mechanical Engineering, (1992).

[3] C. Christensen, Federal Energy Management Program: Transpired Collectors (Solar Preheaters for Outdoor Ventilation Air). (1998) Available from: http://www.eere.energy.gov/femp/pdfs/FTA_trans_coll.pdf. Accessed in June, 2010.

[4] C.F. Kutscher, C.Christensen, G. Barker. Unglazed transpired solar collectors: heat loss theory. ASME Journal of Solar Engineering 115 (3), (1993) 182-188.

[5] K. Gawlik, C. Christensen, C.F. Kutscher. A numerical investigation of low-conductivity unglazed, transpired solar air heaters. Journal of Solar Energy Engineering 127, (2005) 153-155.

[6] S.J. Arulanandam, K.G.T. Hollands, E. Brundrett, A CFD heat transfer analysis of the transpired solar collector under no-wind conditions. Solar Energy 67 (1-3), (1999) 93-100.

[7] G.W.E. Van Decker, K.G.T. Hollands, A.P. Brunger. Heat exchange relations for unglazed transpired solar collectors with circular holes on a square or triangular pitch. Solar Energy 71 (1), (2001) 33-45.

[8] The SOLARWALL Solar Heating System, Conserval Engineering Inc., Canada. Available from: <http: //www.solarwall.com/>. Accessed in November, 2001 and June, 2010.

[9] M. Badache. Modélisation et optimisation des performances thermiques d'un mur solaire à perforations (UTC). Masters dissertation, École de technologie supérieure, Department of Mechanical Engineering, (2010).

[10] Norme européenne. 2005. Installations solaires thermiques et leurs composants - Capteurs solaires - Partie 2: Méthode d'essai. Comité Technique CEN/TC 312. <http://enr.cstb.fr/file/rub12_doc106_7.pdf>. Accessed in September, 2009.

[11] M.A., Leon, S. Kumar, Mathematical modeling and thermal performance analysis of unglazed transpired solar collectors, Solar Energy, 81(1), (2007) 62-75. 